\title{
Present Situation and Countermeasure Analysis of Military Safety Management
}

\author{
Tingkai $\mathrm{Li}^{*}$, Lihong Du, Yingjie Ren
}

$X i$ 'an Institute of High Technology, Xi'an, China

*Corresponding author. Email: 244856049@qq.com

\begin{abstract}
At present, all levels of the army attach great importance of security management. The institution is strictly implemented, and the overall security situation is stable. But the thinking and understanding is not flat, safety training implementation is not strict, security inspection group also is not standard, and the overall requirement of current safety management work, also does not adapt situation task, in this paper the current forces management present situation and the analysis of existing problems, to improve safety management level provides some countermeasures and suggestions.
\end{abstract}

Keywords: Safety management, Army construction, Countermeasure.

\section{部队安全管理现状及对策分析}

\author{
李廷锴, 杜荔红, 任英杰
}

西安高技术研究所, 西安, 中国

*通讯作者. 邮箱: 244856049@qq.com

\section{中文摘要}

当前部队各级对安全管理工作非常重视, 制度落实严格, 安全形势总体平稳。但思想认识还不端正、安全训练 落实还不严格、群防群治建设还有短板, 与安全管理工作的总体要求、形势任务还不相适应, 对此本文就当前 部队管理现状及存在的问题进行分析, 为部队提升安全管理水平提供一些对策建议。

关键词：安全管理，部队建设，对策措施。

\section{1. 引言}

安全管理工作是一项全局性、经常性、综合性的 工作，虽然不是中心中作，但是却对各项工作的开展 有着重要的影响, 部队安全稳定直接关系到良好的部 队营区环境的建设, 关系到广大官兵的身心健康, 因 此安全管理工作是部队完成各项工作任务的基本保 证, 是部队全面建设的“保底工程”。

\section{2. 当前部队管理现状}

\section{1. 管理理念相对滞后}

随着军队社会的不断变革, 安全管理的大环境从 相对封闭到逐步开放, 官兵与外界的交流越来越密切, 人员管控、防间保密的难度越来越大, 传统的管理式 和管理方法已不能很好适应现如今环境, 部队在管理 方法和理念上也开始引入科学管理理论, 重视安全管 理科学, 强调综合对策和管理创新, 但是大部分管理 者未经过相关理论的学习, 组织相关知识的交流、宣 传、培训不足, 在实际工作中依然以经验管理较多, 
对现实存在的不安全因素发现不足, 对突发安全事故 的处置能力不足，对安全事故的后果认识不足。

\section{2. 安全隐患因素增多}

军队新任务、新使命的提出, 使军队各类训练、 演练任务繁重; 执行反恐维稳、抗洪抢险、抗震救灾、 抗疫援助、维和行动等非战争军事行动增多, 人员、 装备长期处于高强度的 “运动状态”，领导机关对高 度分散的部队管控难度增大 $[1]$, 安全管理多样性、 复杂性、应急性、突变性强 [2], 管理领域逐步拓展, 管理要素大幅增加, 面临的安全风险大幅增加, 潜在 安全隐患增多。

\section{3. 信息传播难以管控}

当今社会已经迈入 “ $5 G$ ” 时代, 网络世界的虚拟 开放深入影响着官兵的价值取向和行为方式, 部分网 络 “负能量” 成为官兵违法违纪的直接诱因, 影响部 队安全管理的外部因素越来越多, 此类情况发现难、 查处难、管控难也成为安全管理的 “绊脚石” ，新型 传播媒介对部队安全稳定的负面影响不可低估。

\section{3. 部队安全管理存在问题}

\section{1. 思想认识还不端正}

一些官兵看待安全管理的观念还停留在旧思维中 没有转变过来，还没有树立起“大安全观”“总体安全 观”, 对各级安全组织在开展安全管理工作中的重要 性认识不清, 导致各类安全组织发挥作用不明显。

\section{2. 安全训练落实不严格}

部分单位组织安全训练没有统一制定计划, 想到 什么抓什么, 遇有问题应急式地抓一抓, 没有把安全 训练这项经常性工作做在平时, 没有切实从提高官兵 安全素质、安全能力上制定措施抓落实, 导致部队安 全训练基础还不牢固。

\section{3. 官兵安全素养还不高}

部分官兵对一些基本安全常识掌握了解不全面却 无知无畏, 对安全技能、突发情况处置等不够熟悉, 安全意识比较淡薄; 对潜在的不安全因素觉察不深, 避险化险能力较弱。

\section{4. 群防群治建设有短板}

个别单位抓安全的方法还在依靠主要责任人管的 低层次徘徊, 其余人员安全素质不过硬, 认为安全是 集体的事、是别人的事与自己关系不大, 懂安全、会 管理的人较少, 群管群防群治队伍建设还有较大差距。

\section{4. 部队安全管理对策措施}

\section{1. 加强科学统筹, 提高安全教育效果}

\subsection{1. 统筹教育安排}

将安全、保密教育纳入年度教育计划, 通盘设计, 细化到月, 结合工作实际, 突出重点, 统一筹划、科 学安排, 并加强检查督导, 压减运动式授课、突击式 教育, 将安全教育贯穿于工作开展全过程、全领域。

\subsection{2. 组织常态教育}

突出安全常识、安全法规、警示案例作为主要学 习内容, 组织安全警示教育, 不断强化官兵安全意识。

\subsection{3. 灵活教育形式}

协调官兵参观驻地看守所、监狱, 形成“身临其境” 的震慑, 筑牢官兵法纪观念。机关及时汇总违规违纪 人员受惩情况, 通报下发部队，警醒官兵引以为戒。

\section{2. 强化常态训练, 抓好安全训练落实}

\subsection{1 细化安全训练计划}

结合年度工作筹划，相关业务科相互配合，以应 急处突、紧急避险、自救互救等为主要内容, 开展好 安全训练工作, 统一制定安全训练计划, 明确时间、 内容、授课人和组织方式, 整体推进安全训练落实。

\subsection{2. 狠抓安全技能训练}

结合新兵训练、士兵退役, 以及任务转换、季节 更替、装备更新等时机，定期组织安全方面的常识教 育, 使官兵熟悉各种事故隐患及注意事项，熟悉突发 情况应急处置方法。实投、实爆等险难课目训练展开 前, 做好模拟训练和特情处置训练, 提升官兵险情处 置能力。 


\section{3. 明晰工作职责, 规范安全检查实施}

\subsection{1. 严格责任落实}

机关部门、业务科严格落实“三管” (管行业必须管 安全、管业务必须管安全、管任务必须管安全） [3] 责任, 抓好本行业本领域安全检查督导; 基层对照安 全管理制度要求抓好安全自查及整改等相关工作落 实。

\subsection{2. 规范组织实施}

组织综合检查时, 由主管安全业务的科室牵头负 责, 制定下发检查实施计划, 联动相关业务科集中组 织实施。组织专项检查时, 由相关业务科负责, 结合 上级要求和部队实际, 组织专项检查、专项整治。组 织日常检查时, 相关业务科对本行业安全工作落实情 况不定期加强检查督导, 综合督查组定期进行部队秩 序检查和以往问题整改“回头看”。

\subsection{3. 严肃追责问责}

按照 “军政主官负总责, 分管领导、业务部门负 专责、现场领导负具体责任” 的要求, 细化任务分工、 量化职责范围、强化责任意识 [3]。对安全管理责任 不落实、履职不到位、纪律不遵守等原因出现重大安 全问题的, 坚持有责必究、依纪的原则, 从严、从快、 从重严肃查究, 形成时时、事事追责问责的高压态势。

\section{致谢}

论文是在杜荔红教授的悉心指导下顺利完成, 杜 教授诲人不倦的精神, 严谨的治学态度, 从容旷达的 人生境界, 深厚的学术造诣都让我受益匪浅, 本次论 文的写作, 倾注了杜教授的大量心血, 在此衷心感谢 杜教授对我的帮助。

\section{REFERENCES}

[1] Wu Jianhong, Wu Qizhi. Several problems to be grasped in current military safety management [J]. Journal of Political Science and Engineering, 2013(01):53.

[2] Wang Bo. Research on Military Safety Management Model [D]. Wuhan: Wuhan University, 2010:44-45.

[3] Jiang Wu. Study on the Countermeasures of Strengthening Army Safety Management under the
New Situation [J]. Journal of Police and Marine Police College, 2013(02):21-23. 